\title{
Modular and Scalable FACTS Systems for Improving Stability in Distribution and Transmission Networks, Using the Example of a STATCOM System in an Offshore Distribution Network
}

\author{
Tobias Funk ${ }^{1}$, René Rund ${ }^{1}$, Thomas Röseler ${ }^{1}$ and Tomaz Pfeifer $^{2}$ \\ ${ }^{1}$ Maschinenfabrik Reinhausen $\mathrm{GmbH}$ \\ Power Quality \\ Alte Chaussee 73, 99097 Erfurt (Germany) \\ Phone number: +49 361 3010346, e-mail: t.funk@reinhausen.com \\ ${ }^{2}$ Reinhausen 2e d.o.o. \\ Technoloski park 24, 1000 Ljubljana (Slovenia) \\ Phone number: +386 82054670, e-mail: t.pfeifer@si.reinhausen.com
}

\begin{abstract}
This article addresses the challenges faced by safe operation of offshore distribution networks supplied from the land, taking into consideration long sea cable connections, variations in supply and feed-in scenarios, and non-linear equipment characteristics. Delivering a suitable topology and variable control parameters, STATCOM systems make a significant contribution to the stable supply of offshore consumers in applications like these, with technical connection conditions taken into account. Using the design process as an example, this article presents various methods for designing and proving the stable operating behaviour of modular and scalable STATCOM systems.
\end{abstract}

\section{Key words}

FACTS, STATCOM, Offshore Networks, Voltage Regulation, RTDS

\section{Introduction}

Since its inception, electronic power equipment has carved out a secure position for itself in distribution and transmission networks. Thanks to affordable IGBT components with low switching losses and high forward currents, powerful STATCOM (static synchronous compensator) systems based on low-voltage technologies can be used cost-effectively for influencing load flows in distribution and transmission networks.

Operating long sea cable connections, variations in supply and feed-in scenarios, and non-linear equipment characteristics give rise to particular challenges when it comes to ensuring safe operation of offshore distribution networks supplied from the land [1].

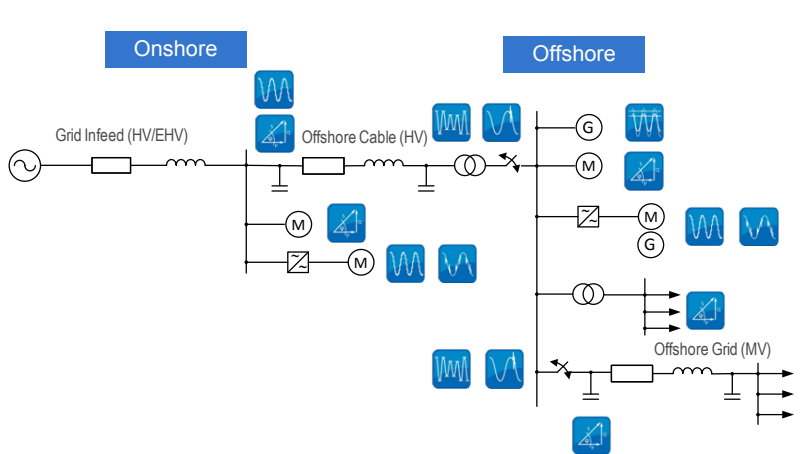

Fig. 1. Example of offshore distribution grid

Delivering a modular topology and variable control parameters, STATCOM systems make a significant contribution to the stable supply of offshore consumers in applications like these, with technical connection conditions taken into account. Mathematical simulations of stationary and transient operating points of the complete system plus verification in a real-time simulator (RTDS) provide key input values that enable optimum parameterization of STATCOM systems. Stable system behavior under low-voltage conditions is proven as part of an integration test with network simulation, using special FRT (fault ride through) tests.

\section{Modular STATCOM System}

The power requirements in offshore distribution networks vary greatly - from a few MVA to upward of 100 MVA. Depending on the short-circuit capacity available to a connection point, even slight changes in load or feed-in characteristics can lead to significant voltage fluctuations and, therefore, unsafe operation. STATCOM systems, 
which enable the dynamic supply of both capacitive and inductive reactive power, are a suitable means of stabilizing system voltage [2]. A modular system design provides a simple way to scale the power of the STATCOM system within the limits of the system technology without the need for additional measures to suit application-specific adaptations (relating to design as well as control and regulation technology) [3].

\section{A. STATCOM Topology}

One example of a modular STATCOM system is based on a complete, three-phase integrated power unit (IPU IGBT power unit) that combines all the components of a 3level IGBT inverter. Twelve IGBTs form the basis of the 3-level IPU circuit (see figure 2). The special circuitry halves the voltage loads on the power semiconductors. This leads to lower losses while also allowing use in grids with a higher rated voltage. The intermediate current voltage is also higher, which in turn allows higher peak currents to be generated - something that is essential for ensuring high dynamic response in the system when compensating for low voltage drops.

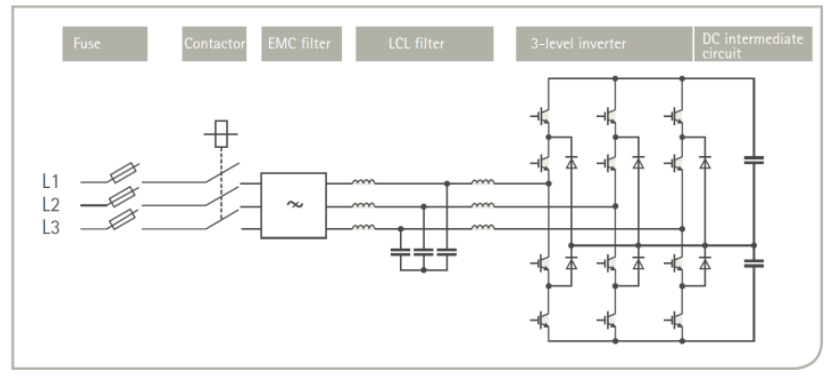

Fig. 2. 3-phase IGBT power unit (IPU)

Another benefit of the 3-level technology is the lower ripple of the output current compared with a 2-level architecture. The divided intermediate circuit and larger number of IGBTs result in an additional third switching state at the output (see figure 3). This enables a more compact design for the network and EMC filters while retaining the same switching frequency, reducing losses as a result.

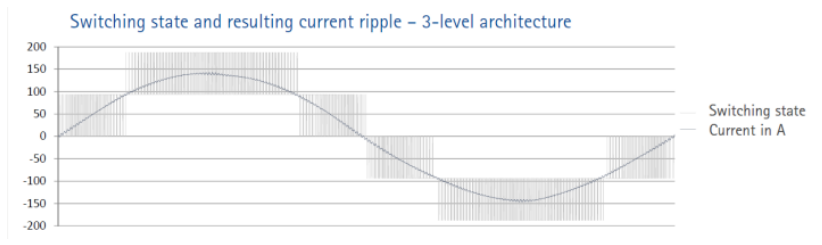

Fig. 3. 3-Level switching topology

Combining all the key elements in a single unit allows 4 IPUs to be connected to a single power module (690 V / $\pm 600 \mathrm{kvar}$ ) in parallel, with up to 6 power modules able to be combined in a STATCOM application with a power level of up to $\pm 3,600 \mathrm{kvar}$ (see figure 4).

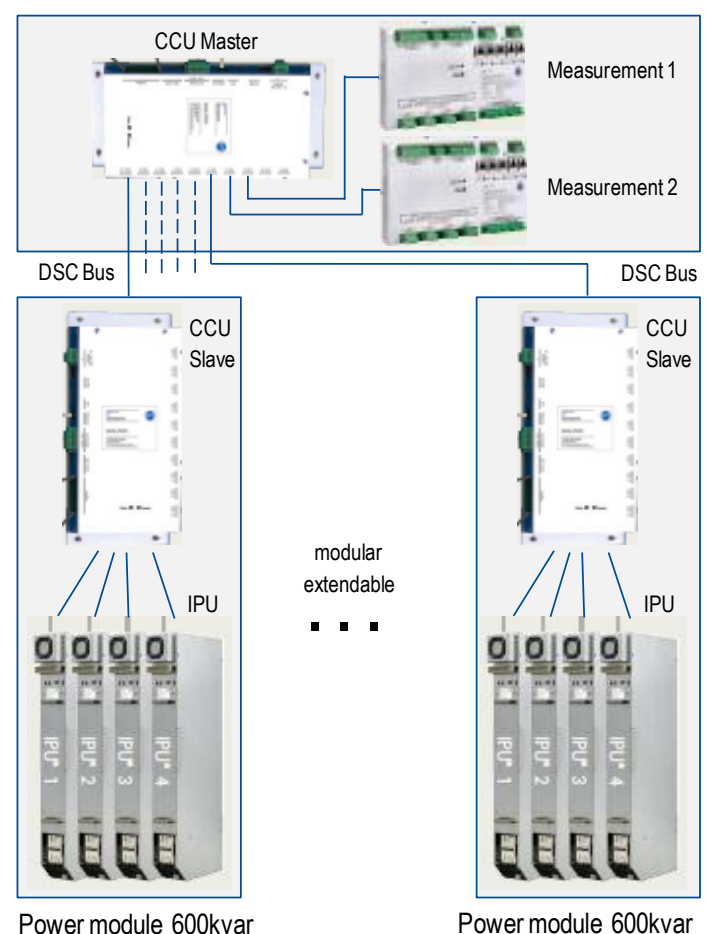

Fig. 4. STATCOM topology with power module and control

\section{B. STATCOM Design Process}

Tailored to the specific application concerned, the design process for modular STATCOM systems involves the following steps:

a. Numerical simulation: Representation of the operating behavior with state differential equations

b. Real-time simulation: Integration of the parameterized STATCOM control into a closed-loop simulation system

c. Laboratory test: Test concerning the effectiveness of the system-critical algorithms implemented in (a) and (b) in laboratory tests

d. Integration test: Integration of the complete system and tests under realistic conditions

\section{Numerical Simulations}

Designing STATCOM systems requires multiple coordinated process steps to develop a solution that is reliable and ideally adapted to the application. These steps are listed below and explained in greater detail in the subchapters that follow:

- Integration of the developed static and dynamic simulation models into realistic network representations in DIgSILENT PowerFactory ${ }^{\circledR}$

- Execution of static network simulations (including load flow calculations)

- Execution of dynamic network simulations (frequency range and time range calculations)

- Tests concerning the effects of network resonance and harmonics on the STATCOM system

- Tests concerning the behavior of STATCOM systems during voltage drops (LVRT, FRT) 


\section{A. PowerFactory® STATCOM Model}

Generic models are used to simulate the operating behavior of STATCOM systems. These models can only provide a simplified representation of actual systems, but still demonstrate realistic results.

This process makes it possible to carry out extensive simulations within a reasonable amount of time in order to analyze the voltage-stabilizing effect of STATCOM systems in different network configurations.

The generic STATCOM model used in the offshore project comprises a pulse-width modulation (PWM) converter, an intermediate DC voltage circuit, and a LCL filter on the network. The PWM converter is modeled as a controlled voltage source with sinusoidal pulse-width modulation.

The intermediate DC voltage circuit and LCL filter are factored into the model based on a real hardware implementation scenario. The real control structure is integrated into the generic STATCOM model based on the environment within PowerFactory ${ }^{\circledR}$ for implementing control models. The IPU control comprises an external and internal control loop (see figure 5).

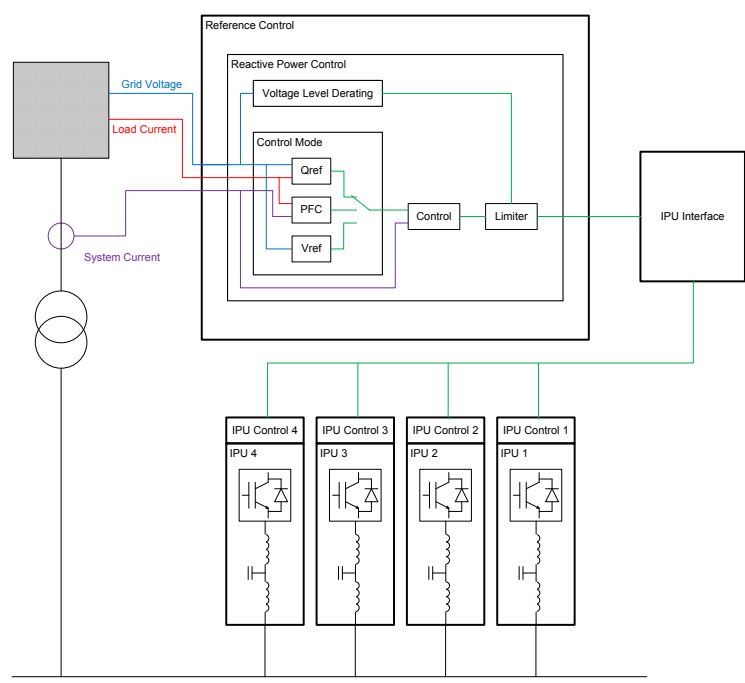

Fig. 5. STATCOM control structure (as a diagram)

The external control loop shows the measured value consumption and measured value processing as well as the reference value control ( $\mathrm{Q}$ control, $\mathrm{U}$ control, $\cos (\varphi)$ control). The resulting reference value is transmitted to the IPU controller via the IPU interface. There, factors including the main current regulator, the DC voltage regulator, and IGBT activation are implemented.

Despite the limitations of the software in implementing the model, the dynamic behavior is shown realistically according to the expected step responses.

\section{B.Load-Flow Calculations}

The first step in designing STATCOM systems involves calculating load flow so that the power flows in the network as well as the grid voltages can be analyzed statically, taking various network configurations and load conditions into consideration.
The extensive calculations required by this offshore project show that operating without STATCOM would lead to permissible voltage ranges being exceeded. Under maximum load conditions, the rated voltage is expected to drop to $0.879 \mathrm{pu}$ in this offshore distribution network. With the implementation of a STATCOM system, the grid voltage can be stabilized and kept within the permissible range.

\section{Analysis of Impedance-Frequency-Characteristics}

During harmonics simulations, analyzing impedance frequency characteristics is an especially vital part of designing STATCOM systems. This process investigates both the effect of network resonance on the load of the LCL circuit and the retroactive effect of the LCL circuit on network impedance.

Figure 6 shows the impedance frequency characteristics (IFC) simulated for the normal network condition in the offshore network in question.

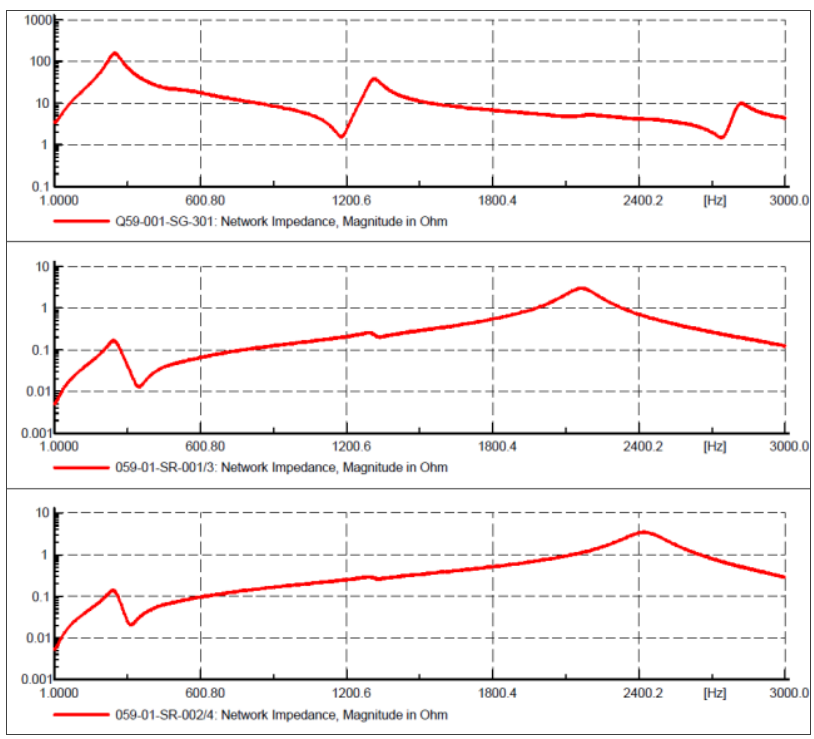

Fig. 6. Calculated IFC in the offshore distribution network

Due to the low short-circuit capacity and long cable sections it is possible to identify a resonance of around $300 \mathrm{~Hz}$ (5th harmonic at a network frequency of $60 \mathrm{~Hz}$ ) in both the medium and low voltage. In order to avoid impermissible STATCOM effects, the control topology was successfully optimized as part of the design process.

\section{Dynamic Simulations}

In addition to observing static operating cases and performing tests relating to network resonances and harmonics, dynamic simulations are a key stage in the process of designing STATCOM systems. These are carried out in the frequency or time range according to the application. It is possible to simulate phenomena including the following:

- Voltage drop during motor start-up

- Voltage drop when transformers and cable sections are switched on (inrush) 
- Voltage increase during load shedding

- Voltage regulation during emergency platform operation

- Operating behaviors during LVRT and FRT

Figure 7 shows the simulated time curves for the grid voltage when the motor starts up, with and without STATCOM.

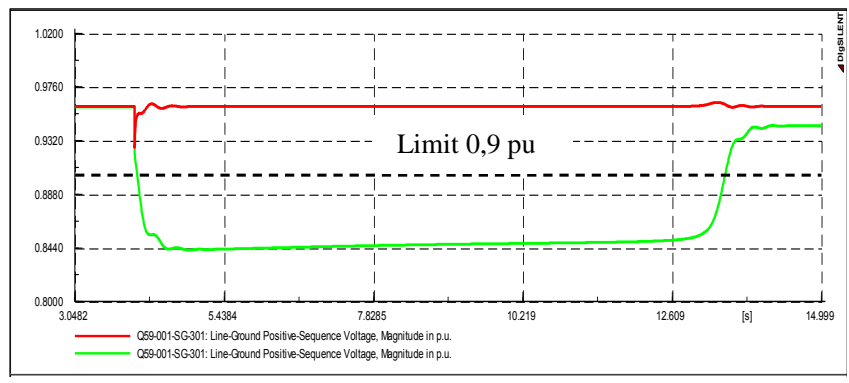

Fig. 7. Voltage drop during 5 MW motor start-up (green: without STATCOM; red: with STATCOM)

The voltage-stabilizing effect can be seen clearly; the voltage drop can be minimized by approximately $15 \%$ to $7 \%$ (limit value: $10 \%$ ). The permissible voltage range is therefore also adhered to during dynamic processes in the network.

The behavior of the STATCOM under low-voltage conditions (LVRT and FRT) is described in detail in chapter 5 .

\section{Real-Time Simulations}

Real-time digital simulators (RTDS) make it possible to simulate electromagnetic processes based on real-time calculations, taking real hardware into consideration. The standard simulation step size is approximately $50 \mu \mathrm{s}$; when it comes to modeling electronic power elements such as IGBT converters, the simulation step sizes are reduced to $1.5 \mu$ s to achieve sufficient precision.

Additional hardware makes it possible for signals to be imported from and exported to external devices. This forms the basis for testing external hardware (such as STATCOM controllers) in a closed control circuit within an electrical simulation environment.

If external signals can be connected to the RTDS, it is then possible to perform hardware-in-the-loop (HIL) tests. During these tests, a section of the network model is replaced with real components and coupled with the simulator. External signals can be imported through analog and digital input cards and the front operating panel.

\section{A RTDS Model}

RSCAD software is a key element in the RTDS system for simulating time ranges. It provides internal monitoring functions as well as the ability to monitor system parameters using external devices (such as oscilloscopes). RSCAD software also makes it possible to model electrical networks in the RTDS. Network elements such as transformers, cables, and generators are represented in libraries.
Cable sections can be represented by means of traveling wave models (split parameters) or simplified PI models (concentrated parameters). Traveling wave models are generally suitable for modeling long transmission cables while PI models can also be used for short cable sections. Therefore, in a case involving an example simulation step size of $50 \mu \mathrm{s}$, the PI model needs to represent cable sections that are shorter than $15 \mathrm{~km}$ in the RTDS.

Transformers are integrated into the RTDS using a linear model. It is possible to implement the key parameters, including impedance, magnetization characteristic and no-load losses. The STATCOM is realistically modeled in the RTDS as a 3-level converter, in the same way as in DIgSILENT PowerFactory $^{\circledR}$ (see figure 8).

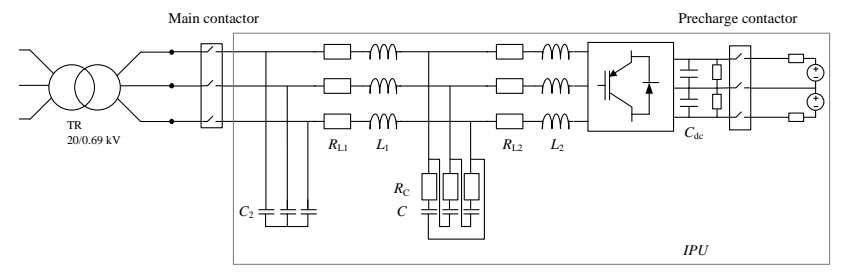

Fig. 8.: STATCOM model in RTDS

The STATCOM model requires low simulation step sizes to represent the IGBT activation and the dynamic system behavior realistically. Due to the comprehensive system architecture in the offshore project being described here, involving 8 or 12 IPU, only one IPU is represented fully in the STATCOM model. The other IPU are duplicated as parallel current sources in the RSCAD software [2].

\section{B RTDS Project Workflow}

Figure 9 shows an overview circuit diagram of a typical RTDS structure.

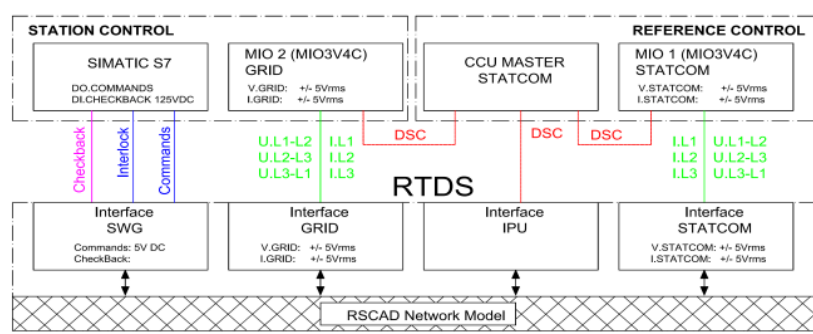

Fig. 9. RTDS test structure

The real STATCOM regulation platform is implemented alongside the protection and regulation modules in the RTDS test environment. The output signals from the STATCOM model required in the STATCOM controller (voltages, currents, and other variables) must be suitably converted. For this purpose, the signals are amplified in various interfaces and integrated into the hardware platform. In turn, the ignition pulses are fed back to the RTDS system in the hardware platform via digital input cards. 


\section{Challenges}

The RTDS test results are based on extensive test programs, enabling a range of operating cases, control behaviors, and fault states (LVRT, FRT), including the UI curve, to be analyzed.

While the real STATCOM system works with an IGBT frequency of approx. $10 \mathrm{kHz}$, the RTDS tests identified areas of instability from an IGBT frequency of as low as around $3 \mathrm{kHz}$. Noticeably high losses were measured in the PWM converter and these losses have a significant impact on the stability of the controller.

Furthermore, instabilities were detected in the STATCOM control behavior due to incorrect switching pulses. As a result of the low impedance in the LCL filter, these incorrect pulses lead to high amplitudes and a high proportion of harmonics in the IPU output current.

Despite the limitations in the RSCAD software and the challenges in implementing the STATCOM hardware in the RTDS, it was still possible to perform all the necessary tests successfully by integrating a separate HIL system (Typhoon) with a higher frequency [4]. The integration of this system is shown as a diagram in figure 10 below.

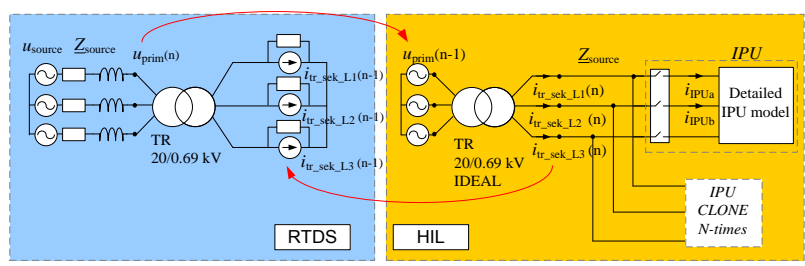

Fig. 10. RTDS/Typhoon interface

\section{RTDS Test Results}

The RTDS test sequence is divided into the following steps:

1. Verifikation of the input conditions

2. Static network calculations (including load flow)

3. Dynamic network calculations (including control

behavior, LVRT, FRT, and overload behavior)

The input conditions are verified by comparing the simulation results in PowerFactory with the RTDS results. In this case, the comparison looked factors including voltage magnitudes, power flows, and impedance frequency characteristics for different load scenarios and switching states in the offshore network. The simulation results of the impedance frequency characteristics are shown in figure 11 .

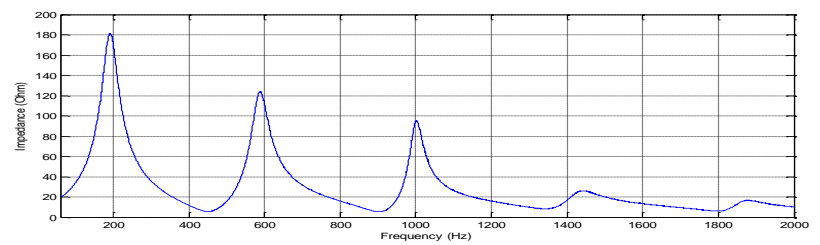

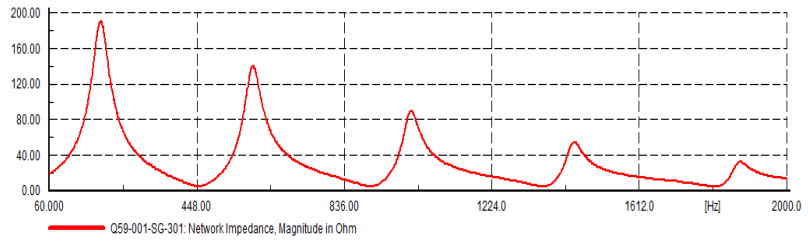

Fig. 11. Comparison of impedance frequency characteristics (Above: RTDS; below: PowerFactory®)

The STATCOM control behavior was evaluated realistically using transient test procedures under various network conditions. Figure 12 shows the step response when the reference value of the STATCOM changes in U control.

The UI curve (figure 12) represents the STATCOM operating behavior in the entire voltage range between $1.1 \mathrm{pu}$ and $0.1 \mathrm{pu}$. The curve shown demonstrates stable functioning at all operating points.

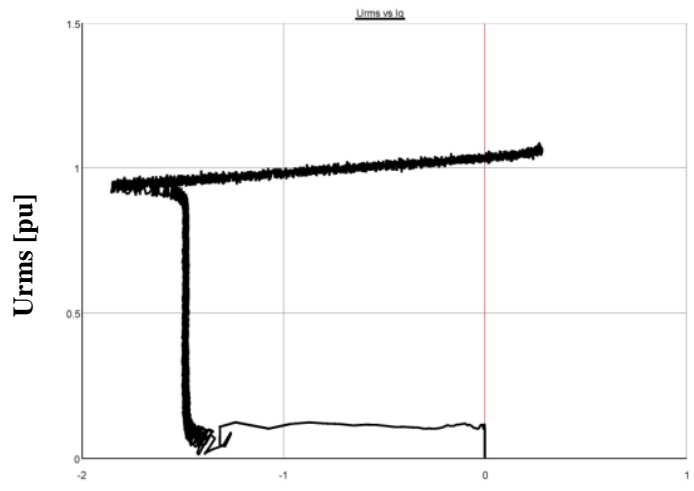

Iq [pu]

Fig. 12. STATCOM UI characteristics in the RTDS

\section{Laboratory Tests}

In addition to the simulations referred to earlier, it is possible to represent the operating states of the entire system through laboratory tests. By way of example, special tests for proving the STATCOM behavior during low-voltage and fault states are described in the sections below.

LVRT and FRT tests are used to prove the safe operation of the modular STATCOM system within a voltage range of $0.0 \mathrm{pu}$ to $1.0 \mathrm{pu}$; the test structure is shown in a diagram in figure 14 . With parametrizable series inductivity, realistic feed-in conditions are set and an adjustable load generates a defined voltage reduction according to the specification:

1. FRT range 1: $0.2 \mathrm{pu} \leq \mathrm{U} \leq 1.0 \mathrm{pu}$ STATCOM PWM is active, Istatcom $\leq$ Irated

2. FRT range 2: $0.0 \mathrm{pu} \leq \mathrm{U} \leq 0.2 \mathrm{pu}$ STATCOM PWM is active, Istatcom $=0(250 \mathrm{~ms})$ 


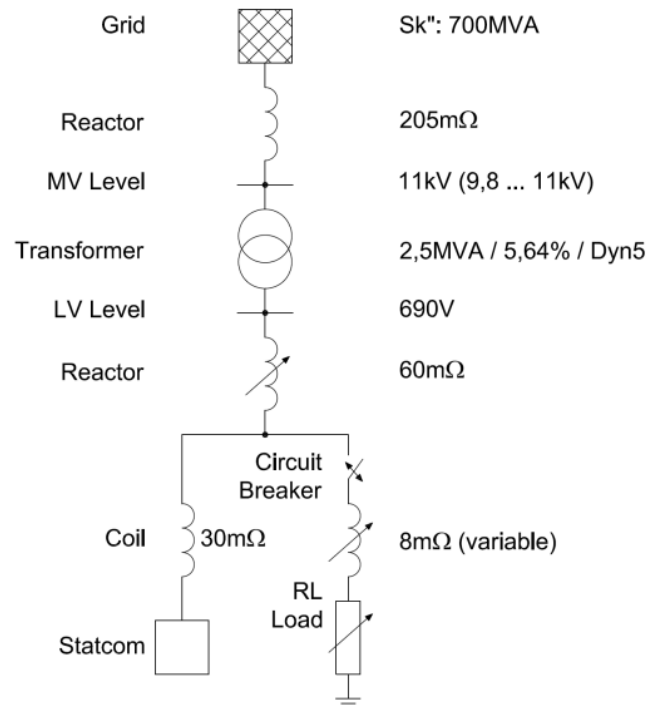

Fig. 13. Overview circuit diagram for the test system

Using a time-controlled approach, the model load was switched on for 50 network periods and the STATCOM behavior was checked.

The specified duration of the fault state corresponds to typical troubleshooting times $(250 \mathrm{~ms})$. The test arrangement is suitable for the FRT test. Evidence has been provided for the following test requirements:

1. 3-phase faults with/without ground involvement

2. 2-phase faults with/without ground involvement

3. 1-phase faults with ground involvement

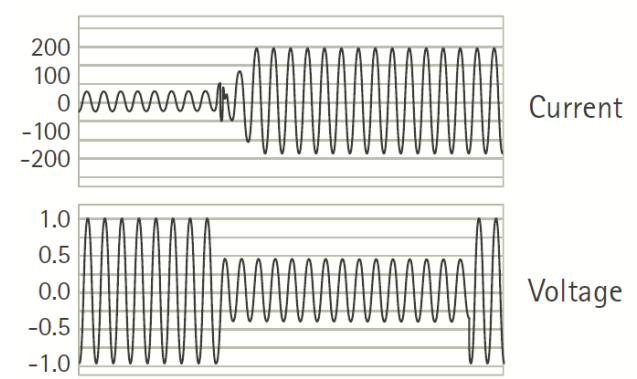

$$
\mathrm{U}_{\text {bus }}>0.2 \mathrm{pu}: \mathrm{I}_{\text {statcom }}>0 \text { continuous }
$$

Fig. 14. STATCOM FRT behavior, range 1 (current in A, voltag in pu)

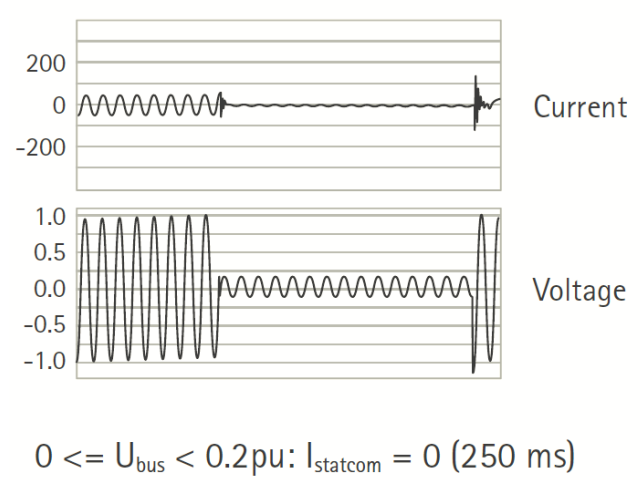

Fig. 15. STATCOM LVRT behavior, range 2 (current in $\mathrm{A}$, voltag in $\mathrm{pu}$ )
The dominance of permanent and transient voltage drops presents a challenge for modular STATCOM systems. The trials carried out at a test institute prove that even modular and scalable STATCOM systems are able to meet specific requirements for operational safety and tolerance with respect to network faults.

\section{Outlook}

Offshore distribution networks place specific requirements on the safe operation of processes receiving a supply. In these cases, using modular and scalable STATCOM systems makes it possible to create attractive solutions for a stable energy supply, taking into consideration volatile network supplies, network resonance, and the demand for robustness with respect to network faults. In the future, applying complex methods and procedures during the design process will need to be a particular focus of attention, so that system design and operational management can be informed by the requirements placed on the network connection point.

\section{References}

[1] Röseler, Th.: FACTS Anwendungen in OffshoreNetzen [FACTS Applications in Offshore Networks]. ECPE cluster seminar "Netzbetrieb bei hohem Leistungselektronikanteil" ["Network Operation With Extensive Power Electronics"]. Würzburg, Germany, 2015.

[2] Ziemke, I., et. al.: Modular STATCOM systemsInnovative power quality solution in industrial projects, "20th Conference of the Electric Power Supply Industry (CEPSI)", International Convention Center JEJU, Korea, 2013.

[3] V. Dinavahi, R. Iravani, R. Bonert, Richard, 2004, "Design of a real-time digital simulator for a DSTATCOM system, "IEEE Transactions on Industrial Electronics, vol. 51, pp. $1001-1008$.

[4] W. Ren, M. Steurer, and T. L. Baldwin, 2008, "Improve the stability and accuracy of power hardware-in-the-loop simulation by selecting appropriate interface algorithms," IEEE Transactions on Industry Applications, vol. 44, pp. $1286-1294$ 